\title{
Desenvolvimento Profissional Docente nos Programas de Pós-Graduação em Educação do Nordeste: uma revisão integrativa
}

\begin{abstract}
Resumo: O Desenvolvimento Profissional Docente apresenta-se como uma temática importante para a apreensão do conhecimento científico produzido nas teses dos programas de pós-graduação em educação, uma vez que devemos compreender e ampliar o nosso olhar sobre as produções nesse campo de estudo, com vistas a um fortalecimento e reflexão sobre essa temática no que concerne à formação de professores. Sendo assim, o objetivo geral deste estudo é investigar a produção científica nos programas de pós-graduação em educação do Nordeste, relativa à temática do Desenvolvimento Profissional Docente. A metodologia utilizada foi uma revisão de literatura do tipo integrativa e, como lócus para o levantamento bibliográfico, utilizou-se os bancos de teses dos programas de pós-graduação em educação da Região Nordeste, com nota Qualis Capes 5. Foram utilizados os seguintes descritores: "Desenvolvimento Profissional Docente" e "Desenvolvimento Profissional de Professores". Após análise inicial, 20 teses atenderam aos critérios de inclusão, as quais foram lidas e a partir das quais foi feita uma análise reflexiva. Como conclusão, aprende-se que a Pós-Graduação em Educação da Universidade Estadual do Ceará é o programa com mais teses defendidas que abordam a temática do desenvolvimento profissional docente, e que existe uma escassez de trabalhos sobre o tema nos demais programas investigados. As teses que tinham como objeto de estudo o Programa Institucional de Bolsas de Iniciação à Docência foram as que discutiram com maior profundidade o tema Desenvolvimento Profissional Docente e, em algumas teses, a formação de professores está diretamente ligada a este Desenvolvimento, compreendendo que este é amplo e vai além da referida formação.
\end{abstract}

Palavras-chave: pesquisa; pós-graduação; desenvolvimento profissional docente; revisão integrativa.

\section{Introdução}

O Desenvolvimento Profissional Docente (DPD) constitui um elemento importante para a compreensão sobre a formação de professores. Contudo, devemos esclarecer que confundir conceitualmente o desenvolvimento profissional docente com a formação de professores é um ato reducionista em relação ao primeiro conceito. Segundo Imbernón (2011, p. 46), “[...] a formação é um elemento importante de desenvolvimento profissional, mas não é o único e talvez não seja o decisivo". Desse modo, esta pesquisa está baseada na produção de conhecimento científico nos programas de pós-graduação em educação da Região Nordeste, como pressuposto de uma reflexão sobre as teses nos doutorados desses programas,
Thaidys da Conceição Lima do Monte

Universidade Estadual do Ceará (UECE)

thaidyslima@hotmail.com Heraldo Simões Ferreira Universidade Estadual do Ceará (UECE)

heraldo.simoes@uece.br Giovana Maria Belém Falcão Universidade Estadual do Ceará (UECE)

giovana.falcao@uece.br 
compreendendo que estes se constituem como espaços de produção do conhecimento no campo da Educação, fomentando uma reflexão na área de formação de professores e desenvolvimento profissional docente.

Nesse contexto, para a compreensão sobre o tema Desenvolvimento Profissional Docente, aportamos conceitualmente em Garcia (1999), uma vez que esse autor defende que o desenvolvimento profissional é compreendido como "[...] um conjunto de processos e estratégias que facilitam a reflexão dos professores sobre a sua própria prática, que contribui para que os professores gerem conhecimento prático". (GARCIA, 1999, p. 144) O autor aponta ainda o desenvolvimento profissional docente como um processo pautado na reflexão da práxis do professor, como elemento formativo.

Sendo assim, apreendemos que a produção do conhecimento deve provocar uma mudança em relação às temáticas discutidas atualmente na sociedade acadêmica, o que nos leva a compreender que nos programas de pós-graduação em educação, que possuem como foco a formação de professores, essa produção científica pode ampliar as discussões sobre o DPD.

Para Garcia (1999), o DPD possui uma relação intrínseca com outros aspectos que reverberam nesse campo do conhecimento, dentre eles a melhoria nas condições de trabalho, maiores possibilidades de ampliação da autonomia docente e a capacidade dos professores de ação individual e coletiva.

Assim, conhecer o que vem sendo produzido na área da Educação sobre o desenvolvimento profissional nos programas de pós-graduação da região Nordeste, com conceito Qualis Capes 5, ${ }^{1}$ justifica-se no sentido de ampliar as discussões e reflexões sobre a importância do DPD para perceber o foco e também as lacunas dessa produção científica, com vistas a fomentar uma reflexão pautada na constituição de novos conhecimentos para a área da Educação.

Nesse sentido, como objetivo geral para esse estudo pretendemos: investigar a produção científica nos programas de pós-graduação em Educação do Nordeste sobre a temática do DPD.

Sobre as pesquisas do tipo revisão integrativa, Mendes, Silveira e Galvão (2008, p. 759) explicam que "Este método de pesquisa permite a síntese de múltiplos estudos publicados e possibilita conclusões gerais a respeito de uma particular área de estudo" e André (2009, p. 43) destaca a relevância de trabalhos desse tipo 
por serem úteis e fornecerem importantes elementos "[...] para aperfeiçoar a pesquisa num determinado campo do saber".

Assim, nossa caminhada investigativa se pauta em coletar, organizar e posteriormente analisar a produção científica em nível de doutorado no campo da Educação. Com o intuito de focalizar nosso olhar investigativo sobre os trabalhos inventariados, apresentamos como pergunta norteadora: como estão as produções científicas sobre DPD nas teses de doutorado dos programas de pós-graduação em educação do Nordeste?

\section{Metodologia}

Como pressuposto metodológico para a investigação científica, esta é uma pesquisa bibliográfica do tipo revisão integrativa, segundo protocolo sugerido por Souza, Silva e Carvalho (2010) para esse tipo de investigação, constituído de seis passos, a saber: a) elaboração da pergunta norteadora; b) busca ou amostragem na literatura; c) coleta de dados; d) análise crítica dos estudos incluídos; e) discussão dos resultados; f) apresentação da revisão integrativa.

Com a finalidade de pesquisar na área da Educação, utilizamos como base de dados os bancos de teses dos programas de pós-graduação em educação da Região Nordeste. Como recorte temporal para as buscas, usamos as teses das turmas de 2013 e 2014 que foram defendidas em 2017 ou 2018. Esse recorte foi escolhido por constituir o período em que as turmas de doutorado tinham apresentado suas teses em todos os programas investigados. Como justificativa para a escolha dos programas de pós-graduação a serem investigados na Região Nordeste, usamos o indicador Qualis Capes 2016 com nota 5, por entender que essa avaliação qualifica e seleciona os programas bem avaliados e, por conseguinte, com maior respaldo na comunidade científica e acadêmica, e por ser o qualis comum aos programas selecionados.

Assim, após definidos os critérios de inclusão, os programas investigados foram: Programa de Pós-Graduação em Educação da Universidade Estadual do Ceará da (PPGE/UECE), Programa de Pós-Graduação em Educação da Universidade Federal do Rio Grande do Norte (PPGEd/UFRN), Programa de Pós-Graduação em Educação e Contemporaneidade da Universidade do Estado da Bahia (PPGEduC / UNEB), Programa de Pós-Graduação em Educação da Universidade Federal de Pernambuco (PPGEdu/UFPE) e Programa de Pós-Graduação em Educação da Universidade Federal da Bahia (PPGE/UFBA). 
Para as buscas, foram utilizados os seguintes descritores: "Desenvolvimento Profissional Docente" e "Desenvolvimento Profissional de Professores", que deveriam aparecer em alguma parte do texto da tese, no corpo do texto ou em seu título. Nesse sentido, realizou-se uma busca no documento com a ferramenta de pesquisa, digitando os referidos termos sem aspas, e, posteriormente, os trabalhos em que esses descritores apareceram foram selecionados para uma análise mais criteriosa.

\section{Resultados e discussões}

Iniciaremos a apresentação dos resultados a partir do levantamento quantitativo dos trabalhos mapeados nos programas de pós-graduação em educação do Nordeste com nota 5 pela Capes, que são: PPGE/UECE, PPGEd/UFRN, PPGEduC / UNEB e PPGE/UFPE. Para o PPGEdu/UFPE, apesar de este ter nota 5 e estar dentro dos critérios de inclusão, não foi possível acessar o banco de teses para o levantamento da pesquisa. Já o PPGE/UFBA, por sua vez, não apresenta ainda disponível em seu banco de teses os trabalhos defendidos em 2018 até o momento em que o levantamento para esta pesquisa foi realizado.

Quadro 1 - Teses mapeadas nos Programas de Pós-Graduação em Educação do Nordeste com conceito Capes 5 julho/2018

\begin{tabular}{|l|c|c|c|}
\hline Programa de & $\begin{array}{c}\text { Ano de } \\
\text { Ingresso } \\
\text { da turma }\end{array}$ & $\begin{array}{c}\text { Quantidade } \\
\text { de Teses } \\
\text { Defendidas }\end{array}$ & $\begin{array}{c}\text { Quantidade } \\
\text { de Teses } \\
\text { Selecionadas }\end{array}$ \\
\hline \multirow{3}{*}{ PPGE / UECE } & 2013 & 12 & 07 \\
\cline { 2 - 4 } & 2014 & 12 & 06 \\
\hline \multirow{3}{*}{ PPGEd/UFRN } & 2013 & 18 & 03 \\
\hline \multirow{3}{*}{ PPGEduC / UNEB } & 2014 & 04 & 00 \\
\hline & 2013 & 19 & 04 \\
\cline { 2 - 4 } & 2014 & 04 & 00 \\
\hline \multirow{2}{*}{ PPGEdu/UFPE } & 2013 & 01 & 00 \\
\hline TOTAL & 2014 & 00 & 00 \\
\cline { 2 - 4 } & & 69 & 20 \\
\hline
\end{tabular}

Fonte: elaborado pelos autores (2021).

Os trabalhos defendidos e disponibilizados nos bancos de teses dos programas de pós-graduação em educação da Região Nordeste das turmas de 2013 e 2014 totalizaram 69 teses, sendo 24 
no PPGE/UECE, 22 no PPGEd/UFRN, 23 no PPGEduC UNEB e 01 no PPGEdu/UFPE.

Após análise mais aprofundada, com a realização de leitura do resumo e posteriormente do texto para identificar a relevância e contexto apresentado sobre a temática do DPD, os trabalhos selecionados totalizaram 20 teses, sendo 13 no PPGE/UECE, 03 no PPGEd/UFRN e 04 no PPGEduC/UNEB.

Com base nos dados apresentados, observa-se que, mesmo sendo o programa de pós-graduação da PPGE/UECE um dos mais recentes, dentre os investigados, é o que possui mais teses que atendem aos critérios estabelecidos por esta pesquisa, totalizando 13 teses defendidas. Isso ocorre, talvez, devido ao fato desse programa ter como área de concentração a Formação de Professores, que de certa forma está ligada, mesmo que não de forma exclusiva, ao DPD.

Outro dado que pode explicar essa expressiva defesa de teses que abordam a temática do DPD é o fato de que o PPGE/UECE realizou investigação em rede apoiada pelo Programa Observatório da Educação (OBEDUC/Capes) no período de 2013 a 2016, cuja pesquisa teve por título Desenvolvimento profissional docente e inovação pedagógica: estudo exploratório sobre as contribuições do Pibid. A iniciativa envolveu três instituições de ensino superior: UECE, UFOP e UNIFESP.

Em relação aos demais programas, não encontramos uma expressiva produção científica com a temática sobre DPD em termos quantitativos, se comparados com o PPGE/UECE.

Quadro 2 - Descrição dos trabalhos mapeados no Programa de Pós-Graduação em Educação PPGE/UECE, turmas de 2013 e 2014, com os descritores

"Desenvolvimento Profissional Docente" e "Desenvolvimento Profissional de Professores" julho/2018

\begin{tabular}{|l|l|l|}
\hline AUTOR (A) & TÍTULO & OBJETIVO \\
\hline $\begin{array}{l}\text { MENEZES } \\
(2017)\end{array}$ & $\begin{array}{l}\text { A Pesquisa como } \\
\text { potencializadora da } \\
\text { reflexão crítica sobre } \\
\text { a formação e a prática } \\
\text { docente: um olhar } \\
\text { sobre a experiência } \\
\text { formativa do Pibid - } \\
\text { UECE }\end{array}$ & $\begin{array}{l}\text { Entender se nas atividades formativas } \\
\text { desenvolvidas no programa Pibid, } \\
\text { no âmbito da UECE, a pesquisa se } \\
\text { estabelece como um veículo para a } \\
\text { promoção da reflexão crítica sobre a } \\
\text { prática docente. }\end{array}$ \\
\hline $\begin{array}{l}\text { FALCÃO } \\
(2016)\end{array}$ & $\begin{array}{l}\text { Ser professor } \\
\text { supervisor do Pibid: } \\
\text { movimentos na } \\
\text { constituição identitária }\end{array}$ & $\begin{array}{l}\text { Compreender o processo de constituição } \\
\text { identitária do professor da Educação } \\
\text { Básica participante do Pibid a partir dos } \\
\text { significados e sentidos produzidos sobre } \\
\text { ser professor supervisor. }\end{array}$ \\
\hline
\end{tabular}




\begin{tabular}{|c|c|c|}
\hline $\begin{array}{l}\text { MEDEIROS } \\
(2017)\end{array}$ & $\begin{array}{l}\text { Significados e } \\
\text { sentidos do currículo } \\
\text { de licenciatura: o que } \\
\text { dizem os professores } \\
\text { formadores de um } \\
\text { curso de Ciências } \\
\text { Biológicas Fortaleza - } \\
\text { Ceará } 2017\end{array}$ & $\begin{array}{l}\text { Conhecer as concepções dos docentes } \\
\text { com relação ao currículo de Licenciatura, } \\
\text { captar suas ideologias subjacentes, } \\
\text { identificar as forças que interferem na } \\
\text { sua prática pedagógica e compreender } \\
\text { como têm se relacionado à construção } \\
\text { identitária sobre a docência. }\end{array}$ \\
\hline $\begin{array}{l}\text { RIBEIRO } \\
\text { (2017) }\end{array}$ & $\begin{array}{l}\text { Memórias de práticas } \\
\text { docentes no Proeja: } \\
\text { IFMA Campus São } \\
\text { Luís Monte Castelo }\end{array}$ & $\begin{array}{l}\text { Conhecer as práticas docentes no } \\
\text { PROEJA, através dos relatos de memória } \\
\text { dos professores que atuam no Programa, } \\
\text { para contribuir com aqueles docentes } \\
\text { que têm dificuldades para trabalhar na } \\
\text { modalidade EJA. }\end{array}$ \\
\hline $\begin{array}{l}\text { BARROS } \\
(2017)\end{array}$ & $\begin{array}{l}\text { O lugar do educando } \\
\text { (Outro) na atuação e } \\
\text { formação do educador } \\
\text { bacharel áltero (Eu) }\end{array}$ & $\begin{array}{l}\text { Analisar o discurso do docente- } \\
\text { bacharel sobre sua atuação e formação, } \\
\text { considerando a dimensão do educando } \\
\text { enquanto outro, na perspectiva da ética da } \\
\text { alteridade radical. }\end{array}$ \\
\hline $\begin{array}{l}\text { RODRIGUES } \\
(2016)\end{array}$ & $\begin{array}{l}\text { Tessituras da } \\
\text { racionalidade } \\
\text { pedagógica na } \\
\text { docência universitária: } \\
\text { narrativas de } \\
\text { professores } \\
\text { formadores }\end{array}$ & $\begin{array}{l}\text { Compreender a trajetória de formação } \\
\text { profissional de professores formadores, } \\
\text { identificando aspectos da racionalidade } \\
\text { pedagógica emergente de aprendizagens } \\
\text { suscitadas na orientação de iniciação à } \\
\text { docência no Pibid. }\end{array}$ \\
\hline $\begin{array}{l}\text { GRANGEIRO } \\
(2017)\end{array}$ & $\begin{array}{l}\text { A didática do } \\
\text { professor formador: } \\
\text { concepções e práticas } \\
\text { pedagógicas para o } \\
\text { ensino superior }\end{array}$ & $\begin{array}{l}\text { Analisar a prática pedagógica do } \\
\text { professor formador a partir do referencial } \\
\text { teórico sobre o tema e das reflexões de } \\
\text { docentes e discentes, tendo a Bricolagem } \\
\text { como apoio metodológico para maior } \\
\text { compreensão do objeto de estudo. }\end{array}$ \\
\hline $\begin{array}{l}\text { TAVARES } \\
(2017)\end{array}$ & $\begin{array}{l}\text { História comparada } \\
\text { da constituição de } \\
\text { saberes docentes } \\
\text { no Brasil e em Cabo } \\
\text { Verde }(1990-2010)\end{array}$ & $\begin{array}{l}\text { Compreender como os egressos do Curso } \\
\text { de Pedagogia da UECE e do Curso de } \\
\text { Licenciatura em Educação Básica do IUE } \\
\text { se mobilizam e se apropriam dos saberes } \\
\text { da formação inicial, para exercerem a } \\
\text { prática pedagógica nas séries iniciais da } \\
\text { educação básica. }\end{array}$ \\
\hline $\begin{array}{l}\text { ROCHA } \\
\text { (2018) }\end{array}$ & $\begin{array}{l}\text { Narrativas de } \\
\text { professores } \\
\text { em situação de } \\
\text { desenvolvimento } \\
\text { profissional: estudo no } \\
\text { contexto do Pibid }\end{array}$ & $\begin{array}{l}\text { Compreender como a inserção no Pibid/ } \\
\text { UECE movimenta o desenvolvimento } \\
\text { profissional de professores da Educação } \\
\text { Básica que atuam como supervisores. }\end{array}$ \\
\hline $\begin{array}{l}\text { CASTRO } \\
\text { (2018) }\end{array}$ & $\begin{array}{l}\text { A práxis pedagógica } \\
\text { e a aprendizagem } \\
\text { contínua da docência: } \\
\text { os saberes da } \\
\text { comunicação e os } \\
\text { saberes da experiência } \\
\text { em interação na } \\
\text { constituição docente }\end{array}$ & $\begin{array}{l}\text { Compreender que aprendizagens } \\
\text { contínuas da docência, explicitadas na } \\
\text { práxis pedagógica, são expressas no } \\
\text { repertório de saberes da experiência na (e } \\
\text { da) comunicação dialógica constituída em } \\
\text { contexto de interação com os discentes } \\
\text { na gestão e na transformação pedagógica } \\
\text { dos conteúdos de ensino. }\end{array}$ \\
\hline
\end{tabular}




\begin{tabular}{|l|l|l|}
\hline CARNEIRO & $\begin{array}{l}\text { A formação didático- } \\
\text { pedagógica e a práxis } \\
\text { dos professores dos } \\
\text { cursos tecnológicos: } \\
\text { estudo na perspectiva } \\
\text { lukacsiana }\end{array}$ & $\begin{array}{l}\text { Compreender, na perspectiva do } \\
\text { pensamento Lukács, na sua obra } \\
\text { "Ontologia do ser social", as implicações } \\
\text { da ausência de uma posição teleológica } \\
\text { específica para a formação didático- } \\
\text { pedagógica dos professores atuantes na } \\
\text { EPT de nível superior na práxis docente. }\end{array}$ \\
\hline SILVA NETA & $\begin{array}{l}\text { O conhecimento } \\
\text { avaliativo dos } \\
\text { docentes dos cursos } \\
\text { de Pedagogia: } \\
\text { cartografia dos } \\
\text { saberes, práticas e } \\
\text { formação }\end{array}$ & $\begin{array}{l}\text { Compreender a constituição do } \\
\text { conhecimento avaliativo dos professores } \\
\text { que lecionavam as disciplinas Didática e } \\
\text { Avaliação nos cursos de Pedagogia da } \\
\text { UECE. }\end{array}$ \\
\hline GONÇALVES & $\begin{array}{l}\text { Formação do } \\
\text { pedagogo para a } \\
\text { gestão escolar na } \\
\text { UAB/UECE: a analítica } \\
\text { da aprendizagem na } \\
\text { educação a distância }\end{array}$ & $\begin{array}{l}\text { Analisar a formação oferecida aos } \\
\text { estudantes da Licenciatura em Pedagogia } \\
\text { a distância da UAB/UECE na área da } \\
\text { gestão escolar e o seu desempenho no } \\
\text { curso, tomando por base a analítica da } \\
\text { aprendizagem. }\end{array}$ \\
\hline
\end{tabular}

Fonte: elaborado pelos autores (2021).

Com base nos trabalhos selecionados no PPGE/UECE, apresentamos a seguir as análises sobre as teses das turmas de 2013 e 2014, levando em consideração o objetivo geral e a contextualização sobre o DPD no texto da tese, destacando os principais pontos, categorias e problematizações.

$\mathrm{Na}$ tese de Menezes (2017), o DPD aparece como uma categoria relacionada à reflexividade. Nela, a autora também traz a temática dentro das discussões realizadas em seu referencial teórico, quando fala sobre o surgimento do Programa Institucional de Bolsas de Iniciação à Docência (Pibid), suas inspirações e princípios norteadores, destacando que esse é um programa pautado no Desenvolvimento Profissional. Utiliza como base teórica para discussão dessa temática autores como Nóvoa (2009a) e Contreras Domingo (2012). Em sua tese, Menezes (2017) destaca ainda que a formação docente se reafirma cada vez mais como uma contribuição importante para o desenvolvimento profissional dos professores, em especial dos coordenadores de área do Pibid.

Em sua investigação, Falcão (2016) aponta o DPD inicialmente em sua justificativa e problematização, ao destacar que sua tese está inserida na linha de pesquisa "Formação e Desenvolvimento Profissional em Educação". A autora esclarece ainda que é preciso olhar para as trajetórias de vida e de desenvolvimento profissional, para que se encontrem elementos que sejam indicativos da constituição da identidade do professor. Além disso, acrescenta que esse 
processo não pode ser realizado desvinculado da reflexão sobre o desenvolvimento profissional. Suas discussões apontam que existe uma interação dos múltiplos saberes dos sujeitos envolvidos no Pibid, o que constitui um elemento relevante para o desenvolvimento profissional dos envolvidos no programa. Como base teórica para a discussão conceitual sobre desenvolvimento profissional, a autora utiliza Nóvoa (2009b), Imbernón (2009) e Garcia (2009).

Para Medeiros (2017), a temática aparece em sua justificativa sobre o objeto de estudo, a qual destaca seu envolvimento e inserção no projeto Desenvolvimento Profissional Docente e Inovação Pedagógica, apoiado pelo OBEDUC, bem como sua participação no grupo de pesquisa Currículo, Subjetividade e Desenvolvimento Profissional Docente. Ainda sobre o Desenvolvimento Profissional Docente, este também é destacado pela autora quando faz uma relação entre o currículo e a formação de professores, apontando as dificuldades que esses professores apresentam para avançar nessas questões devido a uma deficitária formação inicial que reverbera no desenvolvimento profissional dos professores universitários.

Ribeiro (2017) considera que o Programa de Integração da Educação Profissional Técnica de Nível Médio na Modalidade de Educação de Jovens e Adultos (PROEJA) apresenta uma insuficiência em relação à formação inicial, indicando a necessidade de uma formação continuada com o objetivo de se chegar à promoção do desenvolvimento profissional. A autora faz uma relação entre a formação contínua e o desenvolvimento profissional docente, defendendo que a formação continuada se apresenta como uma possibilidade para que os professores possam desenvolver suas formações contínuas e, assim, promover seu desenvolvimento profissional com a participação no PROEJA.

Em seu estudo, Barros (2017) destaca, com base em observações participantes e análise documental, as ações de formação docente na Universidade Federal do Ceará (UFC), mais especificamente no Programa Comunidade de Cooperação e Aprendizagem Significativa (CASa). Como resultados, a pesquisa revelou que um dos motivos que levam os docentes bacharéis a participarem do programa CASa é sua contribuição para o desenvolvimento profissional docente.

Rodrigues (2016) esclarece que sua participação no Pibid contribuiu para seu desenvolvimento profissional e entende que o processo formativo de professores se apresenta apenas como uma etapa do desenvolvimento profissional docente. Além da temática 
aparecer em sua justificativa de tese, ela também é abordada em seus levantamentos bibliográficos, para compreensão do DPD.

Em sua tese, Granjeiro (2017) destaca que seu estudo é feito sobre o professor formador e a temática sobre DPD aparece em subtópico dos resultados do estudo. Para a autora, o desenvolvimento profissional é aquele que se consolida com base em uma postura flexível em relação ao contexto vivenciado na formação do professor atualmente. Apreende ainda que existe uma contribuição para a definição do professor formador quanto ao desenvolvimento profissional de outros professores, fazendo uma relação entre aquele que forma e aquele que é formado.

No estudo de Tavares (2017), o autor aporta em Formosinho (2009) para uma reflexão sobre a formação inicial, sugerindo que esta constitui um momento privilegiado de preparação e de desenvolvimento profissional que vai se incorporando por toda a carreira docente. O autor destaca ainda a relevância dos atuais programas de formação inicial de professores, entendendo que são concebidos sob a premissa do próprio desenvolvimento profissional docente.

Na tese de Rocha (2018), destacamos que o autor também faz parte do grupo OBEDUC e que a temática sobre Desenvolvimento Profissional está destacada no título da tese e em seu objetivo geral. Apreendemos ainda que a investigação se dá em relação ao Pibid/UECE, considerando o desenvolvimento profissional de professores supervisores do programa. O trabalho tem como foco o desenvolvimento profissional, tema que está presente em todo o texto de tese. Como resultado da investigação, o autor sugere que a contribuição para o conhecimento sobre o desenvolvimento profissional docente, no contexto do Pibid, está no fato de que os professores vinculados ao programa passam a incluir melhorias na carreira profissional em seus projetos de vida. Destaca ainda que não é o Pibid que, por si só, desenvolve os professores, mas são os professores que se mobilizam para seu desenvolvimento com base na participação no programa.

Castro (2018) esclarece que sua tese não teve como objetivo realizar discussões, sejam teóricas e empíricas, sobre o desenvolvimento profissional. Contudo, destacamos que o autor aponta a relação existente entre formação contínua e desenvolvimento profissional. Para sua discussão, apreende que é necessária a oferta de forma valorativa ao que os professores sabem e produzem em seu cotidiano, uma vez que essas aprendizagens se inter-relacionam 
com o desenvolvimento profissional. Como resultado, o autor destaca que a formação e a aprendizagem contínua são dimensões interligadas e que possuem singularidades no contexto do desenvolvimento profissional dos professores.

Carneiro (2018), em seu estudo, destaca que, mesmo havendo um crescente em relação à preocupação com a formação e o desenvolvimento profissional de docentes dentro das Instituições de Ensino Superior (IES), bem como nas políticas para esse nível de ensino, os sujeitos que participaram de sua pesquisa não percebem a existência de novas possibilidades de contribuição para uma formação com viés didático-pedagógico, com o intuito de melhoria das práticas docentes dentro das salas de aula. Como resultado, aponta que o Instituto Federal de Educação, Ciência e Tecnologia do Ceará (IFCE) necessita atentar para uma busca e criação de espaço formativo, com vistas à implantação de programas de desenvolvimento profissional dos professores, baseados na indissociabilidade entre ensino-pesquisa-extensão, na relação teoria-prática, na interdisciplinaridade e no trabalho colaborativo.

Silva Neta (2018) destaca que as políticas ou programas de cunho formativo não se constituem como receitas prescritivas sobre a forma de planejar/ensinar/avaliar dos professores, mas que são uma proposição que norteia o caminho de formação dos docentes atuantes no ensino superior, assim possibilitando o desenvolvimento profissional. Como resultado de sua análise, a autora ainda afirma que, em sua busca documental, encontrou indícios de que a UECE possui programas de formação continuada dos docentes de forma descontínua, apreendendo assim que existe uma ausência de continuidade no que se refere ao desenvolvimento profissional docente.

Gonçalves (2018), em sua tese, aponta como pressuposto que a educação continuada e permanente se constitui como um desafio constante para a Educação a Distância (EaD), em especial no que se refere aos sistemas que devem ser promotores do desenvolvimento profissional docente. O autor destaca ainda que é necessário um investimento no desenvolvimento profissional de professores, constituído por valorização, melhoria salarial e das condições de trabalho, sugerindo ainda que se deve implantar um sistema nacional de formação docente em nível superior presencial e a distância.

Nessa perspectiva, algumas teses apresentam uma ligação entre a formação continuada e o desenvolvimento profissional docente. 
Outro aspecto observado com base nas análises é a existência de uma linha dentro do programa de doutoramento, que traz o desenvolvimento profissional docente como foco, o que de certa forma contribui para uma expressiva existência de trabalhos sobre essa temática no PPGE/UECE.

O que podemos apreender de nossas análises é que a temática sobre o desenvolvimento profissional docente nas teses defendidas no PPGE/UECE está ligada às discussões e investigações sobre o Pibid, uma vez que os trabalhos que aportaram nesse campo foram aqueles que trouxeram de forma mais aprofundada o debate sobre o desenvolvimento profissional docente. Destacamos ainda que isso foi apreendido nas teses de Menezes (2017), Falcão (2016), Rodrigues (2016) e Rocha (2018). Outras teses discutem o desenvolvimento profissional docente também pela ótica de outros programas de formação, dentre eles PROEJA e CASa, o que nos leva a uma reflexão pautada em Imbernón (2011, p. 47), ao afirmar que "[...] o desenvolvimento profissional do professor pode ser concebido como qualquer intenção sistemática de melhorar a prática profissional, crenças e conhecimentos profissionais, com o objetivo de aumentar a qualidade docente de pesquisa e de gestão". Isso pode ser vivenciado com a participação em programas de formação continuada, como os que foram apresentados.

Corroborando, Ribeiro e Nogueira (2016) destacam que o Pibid é um programa relevante e que abre possibilidades de pesquisas e estudos, além de proporcionar o DPD aos envolvidos. Isso foi posto também nas teses investigadas que fizeram alusão ao Pibid ou como objeto de estudo ou como elemento de reflexão. Destacamos que existe uma diferença entre o DPD em relação aos professores da Educação Básica e do Ensino Superior no que se refere a autores de base, produção científica, dentre outros aspectos, mas essa diferenciação não foi problematizada pelas autoras das teses investigadas. 
Quadro 3 - Descrição dos Trabalhos mapeados no Programa de Pós-Graduação em Educação PPGEd/UFRN, turmas de 2013, com os descritores

“Desenvolvimento Profissional Docente" e "Desenvolvimento Profissional de Professores" julho/2018

\begin{tabular}{|c|c|c|}
\hline AUTOR (A) & TÍTULO & OBJETIVO \\
\hline $\begin{array}{l}\text { CARVALHO } \\
\text { (2017) }\end{array}$ & $\begin{array}{l}\text { Necessidades formativas } \\
\text { de professores para } \\
\text { o ensino das ciências } \\
\text { da natureza nos anos } \\
\text { iniciais da escolarização: } \\
\text { a classificação como um } \\
\text { saber profissional }\end{array}$ & $\begin{array}{l}\text { Investigar como se configuram as } \\
\text { necessidades formativas de professores } \\
\text { para ensinar ciências da natureza nos } \\
\text { anos iniciais de escolarização, a fim de } \\
\text { oferecer subsídios para uma proposta } \\
\text { de formação continuada. }\end{array}$ \\
\hline $\begin{array}{l}\text { SILVA } \\
(2017)\end{array}$ & $\begin{array}{l}\text { Concepções e práticas da } \\
\text { educação do campo: um } \\
\text { estudo com professores em } \\
\text { formação }\end{array}$ & $\begin{array}{l}\text { Analisar as concepções dos professores } \\
\text { sobre "campo" e as relações que eles } \\
\text { estabelecem entre essas concepções e } \\
\text { suas práticas pedagógicas. }\end{array}$ \\
\hline $\begin{array}{l}\text { CARVALHO } \\
\text { DA SILVA } \\
\text { (2017) }\end{array}$ & $\begin{array}{l}\text { Necessidades de formação } \\
\text { docente de professores } \\
\text { do Pronatec: um estudo } \\
\text { de caso na Educação } \\
\text { Profissional }\end{array}$ & $\begin{array}{l}\text { Investigar necessidades da formação } \\
\text { docente de professores que atuaram } \\
\text { no período de } 2013 \text { a } 2014 \text { na disciplina } \\
\text { Introdução ao Mundo do Trabalho e } \\
\text { Fundamentos da Administração, que } \\
\text { integra o núcleo comum da matriz } \\
\text { curricular do PRONATEC/IFPB. }\end{array}$ \\
\hline
\end{tabular}

Fonte: elaborado pelos autores (2021).

Partindo dos trabalhos selecionadas no PPGEd/UFRN, a seguir fazemos a análise sobre as teses da turma de 2013, uma vez que não foram selecionados trabalhos da turma de 2014, com base nos critérios já descritos anteriormente.

Para Carvalho (2017), o desenvolvimento profissional docente se constitui como uma categoria de análise pautada em Garcia (1999), e que se relaciona com a trajetória de vida do professor. O autor faz ainda uma relação entre a formação e o desenvolvimento profissional, destacando a formação continuada como um processo estratégico de DPD e que tem um papel fundamental na aprendizagem e desenvolvimento profissional, e reafirma que "[...] a formação continuada só será estratégica para uma nova qualidade da prática pedagógica em Ciências da Natureza, ou em qualquer outra área de ensino, quando se voltar para os objetivos do Desenvolvimento Profissional docente considerando suas necessidades formativas...". (CARVALHO, 2017, p. 266)

Silva (2017) aponta em sua tese a proposta de formação contínua e desenvolvimento profissional de educadores do campo - no PPJCST, como sendo uma das ações de educação do campo no Brasil, perpassando uma perspectiva transdisciplinar. A autora 
aporta em Pérez-Goméz (1998), destacando a função do professor e o processo de sua formação e desenvolvimento profissional, dentro de um enfoque pautado na criticidade e na transformação social.

Na tese de Carvalho da Silva (2017), a temática sobre desenvolvimento profissional docente aparece em sua justificativa, relacionando-o à formação de professores e refletindo sobre a formação docente como processo de desenvolvimento profissional. Baseia-se em Imbernón (2011) e nos Referenciais para Formação de Professores para sustentar a defesa da necessidade de uma formação contínua e que se pauta na exigência de investigações relacionadas ao desenvolvimento profissional do professor.

As teses defendidas no PPGEd/UFRN, em que o desenvolvimento profissional docente é apreendido como um elemento constituinte das trajetórias de vida dos professores e relacionado à formação continuada docente, estão fundamentadas em autores como Garcia (1999), Pérez Goméz (1998) e Imbernón (2011). Não existem muitos trabalhos sobre essa temática no programa, o que nos leva a supor a sua necessidade de ampliação nas produções científicas sobre esse tema, uma vez que está relacionado à área da Educação e formação de professores.

Quadro 4 - Descrição dos trabalhos mapeados no Programa de Pós-Graduação em Educação PPGEduC/UNEB, turmas de 2013 e 2014, com os descritores

"Desenvolvimento Profissional Docente" e "Desenvolvimento Profissional de Professores". Julho/2018

\begin{tabular}{|l|l|l|}
\hline AUTOR (A) & TíTULO & OBJETIVO \\
\hline REIS & $\begin{array}{l}\text { Professores de jovens } \\
\text { com doenças falciformes: } \\
\text { contornos, nuances e } \\
\text { imagens de viagem }\end{array}$ & $\begin{array}{l}\text { Compreender como se constituem as } \\
\text { práticas pedagógicas de professores } \\
\text { de jovens com DF matriculados em } \\
\text { escolas da Rede Estadual de Ensino } \\
\text { situadas na região metropolitana de } \\
\text { Salvador-BA. }\end{array}$ \\
\hline $\begin{array}{l}\text { OLIVEIRA } \\
\text { DA SILVA }\end{array}$ & $\begin{array}{l}\text { Formação Docente no Pibid: } \\
\text { temporalidades, trajetórias e } \\
\text { constituição identitária }\end{array}$ & $\begin{array}{l}\text { Compreender a constituição } \\
\text { da identidade docente, a partir } \\
\text { das experiências formativas de } \\
\text { licenciandos em Letras, participantes } \\
\text { do Pibid. }\end{array}$ \\
\hline CORTIZO & $\begin{array}{l}\text { Auctoritas Inter-Rogada: } \\
\text { docência (re)inventada }\end{array}$ & $\begin{array}{l}\text { Analisar a (des)autorização docente } \\
\text { na escola contemporânea, na busca } \\
\text { de desvelar suas implicações no } \\
\text { saber docente. }\end{array}$ \\
\hline
\end{tabular}




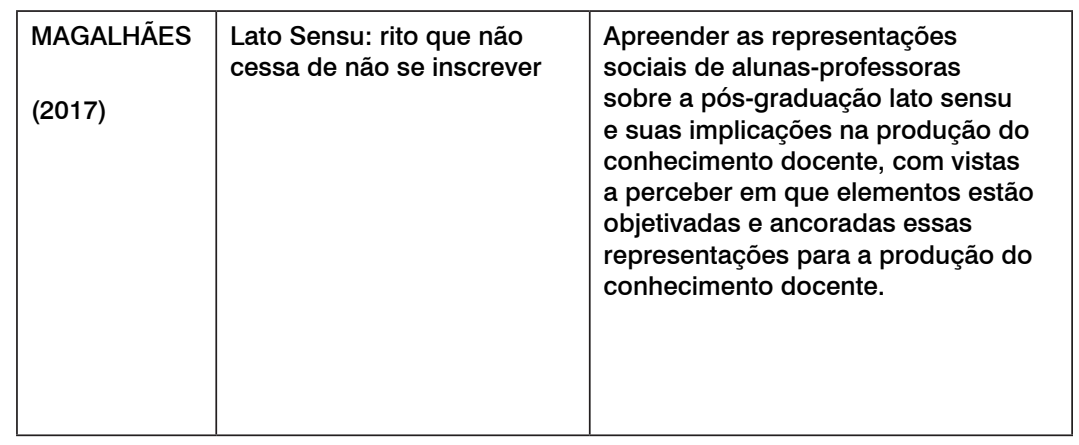

Fonte: elaborado pelos autores (2021).

No PPGEduC/UNEB, analisamos as teses da turma de 2013, pois, assim como no PPGEd/UFRN, não foram selecionadas teses da turma de 2014, por não atenderem aos critérios e não discutirem o desenvolvimento profissional docente nem como foco e nem como categoria tangencial. Assim, apresentamos as análises a seguir.

Para Reis (2017), o investimento na formação docente gera um impacto na melhoria da qualidade do ensino. Contudo, destaca que isso não é uma solução definitiva e que um projeto no âmbito educacional de reformas deve contemplar o desenvolvimento profissional docente. A tese ainda amplia as discussões, uma vez que está inserida na linha de pesquisa conhecida como Formação de Professores, Desenvolvimento Profissional e Inovações Pedagógicas. O trabalho destaca ainda que a elaboração de processo formativos pode ser útil para o desenvolvimento profissional docente, se isso for um desejo da comunidade escolar

Oliveira da Silva (2017) apresenta Nóvoa (1992) como um aporte para seu referencial teórico em relação ao desenvolvimento profissional docente relacionado à formação de professores. Em um tópico da tese que se refere ao cotidiano escolar como lócus da produção de experiências formativas durante a trajetória na universidade, a autora destaca as aprendizagens experienciais desenvolvidas no Pibid como elemento constituinte para o desenvolvimento profissional docente. Conclui que uma aprendizagem experiencial que seja efetiva na história de formação do professor causará impactos futuramente em seu desenvolvimento profissional.

Na tese de Cortizo (2017), a temática sobre desenvolvimento profissional docente aparece em suas análises sobre as falas dos sujeitos investigados, que trazem uma ligação entre formação e 
desenvolvimento profissional. A autora afirma ainda que o desenvolvimento profissional abarca uma compreensão ampliada que foca também as condições salariais, a estrutura e condições de trabalho, a carreira e o clima organizacional, e que dessa forma a formação continuada é um fator fundamental a ser considerado.

Em sua investigação, Magalhães (2017) apreende que o sujeito deve se comprometer com sua formação, pois está diretamente implicado na mesma e isso se dá quando ele tem ideia de sua necessidade e compreende que a formação faz parte do seu desenvolvimento profissional. Pauta-se em Marcelo Garcia (2009) para reflexões sobre a formação continuada no contexto da pósgraduação lato sensu, destacando que ela precisa suscitar não só questões relacionadas à área pedagógica, mas também aquelas que envolvem as relações pessoais e sociais dos alunos-professores.

Nos trabalhos analisados, o desenvolvimento profissional docente, apesar de aparecer em quatro teses, não se apresenta através de discussões ou reflexões aprofundadas. O Pibid aparece ainda em uma tese que relaciona a participação nesse programa ao desenvolvimento profissional docente e analisa que as reformas educacionais devem contemplar esse desenvolvimento profissional do professor. Além disso, sugere-se que ele deve ser ampliado para além da formação e abranger outros elementos implicados, como valorização profissional, melhores condições de trabalhos, dentre outras. Finalmente, há a necessidade de um comprometimento do professor com sua formação para se chegar a um desenvolvimento profissional.

\section{Considerações finais}

A investigação realizada buscou analisar a produção científica de teses de doutorado dos programas de pós-graduação em educação da Região Nordeste, com conceito Quali Capes 5. Percebemos, pautados na imersão nos bancos de teses dos programas investigados, que apenas em um deles, ou seja, no PPGE/UECE, existe uma expressiva produção de trabalhos que abordam a temática do Desenvolvimento Profissional Docente. Nos demais programas, PPGEd/UFRN e PPGEduC/UNEB, essa produção surge em poucas teses, o que pode ser também um reflexo relacionado ao fato de a pesquisa ter sido realizada apenas com duas turmas de cada programa, para atender os critérios de inclusão já esclarecidos. Esses 
resultados poderão apresentar alteração se a busca for ampliada para todas as turmas.

Apreendemos, com base nos resultados encontrados, que é necessário ampliar os processos reflexivos e de discussão sobre o lugar do DPD nas teses dos programas de Educação, como um elemento necessário à compreensão mais aprofundada sobre essa temática, uma vez que isso pode contribuir com aspectos relacionados ao modo como as instituições de ensino investem em seus docentes, propiciando uma maior participação destes em ações que promovam seu desenvolvimento profissional.

Nesse sentido, a produção científica sobre o desenvolvimento profissional docente se apresenta como uma ponte necessária para que haja uma compreensão sobre o tempo e lugar dessa temática nas produções de teses dos doutores em Educação da Região Nordeste. Compreendemos, com nossos resultados, que o tempo dessas produções precisa ser ampliado e que o lugar que estas ocupam ainda é restrito.

Os bancos de teses se apresentam como um repositório dessas produções científicas, facilitando o conhecimento e o acesso ao que vem sendo produzido atualmente sobre o DPD. Por outro lado, também apreendemos as fragilidades de acesso a alguns bancos de teses, o que pode de certa forma contribuir para uma reflexão sobre as dificuldades implicadas nessa difusão do conhecimento.

Entendemos que novas investigações devem ser feitas para ampliar o olhar sobre as produções de teses na temática do DPD e que a divulgação de mais pesquisas do tipo revisão integrativa é relevante para que se possa formar uma rede de produções e conhecimentos científicos.

\section{Faculty Professional Development on Postgraduate Programs on Education of Northeastern: an Integrative Revision}

\footnotetext{
bstract: Faculty Professional Development presents itself as an important theme for the apprehension of scientific knowledge produced in the dissertations of postgraduate education programs, since we must understand and expand our view on the productions in this field of study, towards strengthening and reflection on this theme with regard to teacher training. Thus, the general objective of this study is to investigate the scientific production in postgraduate programs in education in the Northeast, related to the theme of Faculty Professional Development. The methodology used was an integrative literature review and, as a locus for the bibliographic survey, we used the dissertation banks of postgraduate education programs in the Northeast region,
} 
with a Qualis Capes 5 grade. The following descriptors were used: "Faculty Professional Development" and "Professor Professional Development". After initial analysis, 20 dissertations met the inclusion criteria, which were read and from which a reflexive analysis was made. As a conclusion, we apprehend that the Pós-Graduação em Educação da Universidade Estadual do Ceará is the program with the most defended works that address the theme of faculty professional development, and that there is a scarcity of works of this kind in the other investigated programs. The dissertations that had Programa Institucional de Bolsas de Iniciação à Docência as their object of study were those that discussed in greater depth the theme of Faculty Professional Development and, in some of them, teacher training is directly linked to FPD, understanding that it is broad and goes beyond that training.

Key-words: research; postgraduation; faculty professional development; integrative review.

\section{Desarrollo profesional docente en los programas de posgrado en educación en el noreste: una revisión integradora}

Desarrollo Profesional Docente se presenta como un tema importante para la aprehensión del conocimiento científico producido en las tesis de los programas de educación de posgrado, ya que debemos comprender y ampliar nuestra mirada sobre las producciones en este campo de estudio, con miras al fortalecimiento y reflexionando sobre este tema en lo que respecta a la formación del profesorado. Por tanto, el objetivo general de este estudio es investigar la producción científica en programas de posgrado en educación en el Nordeste, relacionados con la temática de Desarrollo Profesional Docente. La metodología utilizada fue una revisión de la literatura de tipo integrativo y, como locus para la encuesta bibliográfica, se utilizaron los bancos de tesis de los programas de posgrado en educación de la región Nordeste, con grado Qualis Capes 5. Se utilizaron los siguientes descriptores: "Desarrolho profesional docente " $\mathrm{y}$ " Desarrollo profesional docente ". Tras el análisis inicial, cumplieron los criterios de inclusión 20 tesis, las cuales fueron leídas y a partir de las cuales se realizó un análisis reflexivo. Como conclusión, aprehendemos que el Pós-Graduação em Educação Universidade Estadual do Ceará es el programa con más tesis defendidas que abordan el tema del desarrollo profesional docente, y que hay escasez de trabajos sobre el tema en los demás programas investigados. Las tesis que tuvieron al Programa Institucional de Bolsas de Iniciação à Docência como objeto de estudio fueron las que discutieron con mayor profundidad el tema del Desarrollo Profesional Docente y, en algunas tesis, la formación docente está directamente vinculada al DPD, entendiendo que es amplio y va más allá de esa formación.

Palabras clave: investigación; posgraduación; desarrollo profesional docente; revisión integradora. 


\section{Referências}

ANDRÉ, M. E. D. A. A produção acadêmica sobre formação de professores: um estudo comparativo das dissertações e teses defendidas nos anos de 1990 e 2000. Revista Brasileira de Pesquisa sobre a formação de professores, Belo Horizonte, v. 1, n. 1, p. 41-56, 2009.

BARROS, C. de M. P. O lugar do educando (outro) na atuação e formação do educador bacharel áltero (eu). 2017. Tese (Doutorado Acadêmico em Educação) - Universidade Estadual do Ceará, Fortaleza, 2017.

CARNEIRO, I. M. S. P. A formação didático-pedagógica e a práxis dos professores dos cursos tecnológicos: estudo na perspectiva lukacsiana. 2018. Tese (Doutorado Acadêmico em Educação) - Universidade Estadual do Ceará, Fortaleza, 2018.

CARVALHO, C. S. C. Necessidades formativas de professores para o ensino das ciências da natureza nos anos iniciais da escolarização: a classificação como um saber profissional. 2017. Tese (Doutorado Acadêmico em Educação) - Universidade Federal do Rio Grande do Norte, Natal, 2017.

CASTRO, F. M. F. M. A práxis pedagógica e a aprendizagem contínua da docência: os saberes da comunicação e os saberes da experiência em interação na constituição docente. 2018. Tese (Doutorado Acadêmico em Educação) - Universidade Estadual do Ceará, Fortaleza, 2018.

CONTRERAS DOMINGO, J. Autonomia de professores. 2. ed. São Paulo: Cortez, 2012.

CORTIZO, T. L. Auctoritas inter-rogada: docência (re)inventada. 2017. Tese (Doutorado em Educação e Contemporaneidade) - Universidade do Estado da Bahia, Salvador, 2017.

CARVALHO DA SILVA, M. Necessidades de formação docente de professores do Pronatec: um estudo de caso na Educação Profissional. 2017. Tese (Doutorado Acadêmico em Educação) - Universidade Federal do Rio Grande do Norte, Natal, 2017.

FALCÃO, G. M. B. Ser professor supervisor do PIBID: movimentos na constituição identitária. 2016. Tese (Doutorado Acadêmico em Educação) - Universidade Estadual do Ceará, Fortaleza, 2016.

FORMOSINHO, J. Formação de professores: aprendizagem profissional e acção docente. Porto-Portugal: Porto Editora, 2009.

GARCIA, C. M. Formação de professores: para uma mudança educativa. Porto: Porto Editora, 1999.

GARCIA, C. M. Desenvolvimento profissional: passado e futuro. Sísifo Revista das Ciências da Educação, Lisboa, n. 8, p. 7-22, jan./abr. 2009.

GONÇALVES, M. T. L. Formação do pedagogo para a gestão escolar na UAB/UECE: a analítica da aprendizagem na educação a distância. 2018. Tese (Doutorado Acadêmico em Educação) - Universidade Estadual do Ceará, Fortaleza, 2018. 
GRANGEIRO, M. F. A didática do professor formador: concepções e práticas pedagógicas para o ensino superior. 2017. Tese (Doutorado Acadêmico em Educação) - Universidade Estadual do Ceará, Fortaleza, 2017.

IMBERNÓN, F. Formação docente e profissional - formar-se para a mudança e a incerteza. 8. ed. São Paulo: Cortez Editora, 2009.

IMBERNÓN, F. Formação docente e profissional: formar-se para a mudança e a incerteza. 9. ed. São Paulo: Cortez, 2011.

MAGALHÃES, P. M. M. de S. Lato Sensu: rito que não cessa de não se inscrever. 2017. Tese (Doutorado Acadêmico em Educação) Universidade do Estado da Bahia, Salvador, 2017.

MEDEIROS, J. B. L. de P. Significados e sentidos do currículo de licenciatura: o que dizem os professores formadores de um curso de Ciências Biológicas. 2017. Tese (Doutorado Acadêmico em Educação) Universidade Estadual do Ceará, Fortaleza, 2017.

MENDES, K.; SILVEIRA, R.; GALVÃO, C. Revisão integrativa: método de pesquisa para a incorporação de evidências na saúde e na enfermagem. Texto Contexto Enferagem, Florianópolis, v. 17, n. 4, p. 758-764, dez. 2008.

MENEZES, E. A. de O. A pesquisa como potencializadora da reflexão crítica sobre a formação e a prática docente: um olhar sobre a experiência formativa do PIBID-UECE. 2017. Tese (Doutorado Acadêmico em Educação) - Universidade Estadual do Ceará, Fortaleza, 2017.

NÓVOA, A. Vidas de professores. Portugal: Porto, 1992.

NÓVOA, A. Professores, imagens do futuro presente. Lisboa: EDUCA, 2009a.

NÓVOA, A. Para uma formação de professores construída dentro da profissão. Revista Educación, Madrid, n. 350, p. 203-218, set./dez. 2009b.

OLIVEIRA DA SILVA, F. Formação docente no PIBID: temporalidades, trajetórias e constituição identitária. 2017. Tese (Doutorado Acadêmico em Educação) - Universidade do Estado da Bahia, Salvador, 2017.

PÉREZ GOMÉZ, A. I. Compreender o ensino na escola: modelos metodológicos de investigação educativa. In: GIMENO SACRISTÁN, J.; PÉREZ GOMÉZ, A. I. Compreender e transformar o ensino. Porto Alegre; Artmed, 1998. p. 99-117.

REIS, D. S. Professores de jovens com doenças falciformes: contornos, nuances e imagens de viagem. 2017. Tese (Doutorado Acadêmico em Educação) - Universidade do Estado da Bahia, Salvador, 2017.

RIBEIRO, L. A.; NOGUEIRA, E. G. D. O desenvolvimento profissional docente e o PIBID: influências do programa desvelada por seus egressos. Revista Práxis Educacional, Vitória da Conquista, Bahia, v. 12, n. 21, p. 45-74 jan./abr. 2016.

RIBEIRO, V. M. Memórias de práticas docentes no Proeja: IFMA campus São Luís Monte Castelo. 2017. Tese (Doutorado Acadêmico em Educação) - Universidade Estadual do Ceará, Fortaleza, 2017. 
ROCHA, C. C. T. Narrativas de professores em situação de desenvolvimento profissional: estudo no contexto do PIBID. 2018. Tese (Doutorado Acadêmico em Educação) - Programa de Pós-Graduação em Educação, Universidade Estadual do Ceará, Fortaleza, 2018.

RODRIGUES, C. S. D. Tessituras da racionalidade pedagógica na docência universitária: narrativas de professores formadores. 2016. Tese (Doutorado Acadêmico em Educação) - Programa de Pós-Graduação em Educação, Universidade Estadual do Ceará, Fortaleza, 2016.

SILVA NETA, M. de L. da. O conhecimento avaliativo dos docentes dos cursos de Pedagogia: cartografia dos saberes, práticas e formação. 2018. Tese (Doutorado Acadêmico em Educação) - Universidade Estadual do Ceará, Fortaleza, 2018.

SILVA, K. A de L. Concepções e práticas da educação do campo: um estudo com professores em formação. 2017. Tese (Doutorado Acadêmico em Educação) - Universidade Federal do Rio Grande do Norte, Natal, 2017.

SOUZA, M.; SILVA, M.; CARVALHO, R. Revisão integrativa: o que é e como fazer. Einstein, São Paulo, v. 8, n. 1, p. 102-106, mar. 2010.

TAVARES, A. F. L. História comparada da constituição de saberes docentes no Brasil e em Cabo Verde (1990-2010). 2017. Tese (Doutorado Acadêmico em Educação) - Universidade Estadual do Ceará, Fortaleza, 2017.

Submetido: $21 / 07 / 2020$

Aceito: $21 / 05 / 2021$ 